\title{
THE USE OF WORDPROCESSING AND WRITER'S COMPUTER PROGRAMS IN REPORT HRITING
}

\author{
Robert N. Gosselink
}

What do we wish to teach students in a technical report writing course? Surveying the texts from Andrews \& Blickle to UImar and Gould I find the same basics, however differently stated: principles and forms; technique and form; audience, strategy, and applications; process, style, and applications; basic issues, the report (form), and tools and methods (style, mechanics, graphics). That is, we want them to tailor recognizable, acceptable, useful formats to a specific occasion using meaningful, concise, effective prose aided by appropriate graphics. Given a decent textbook and a precise assignment, conscientious students can produce well-documented, appropriately illustrated reports; the instructor, then, need only convince them to believe and act upon the universally acknowledged importance of audience. Writing with the audience in mind involves not only assessing needs, expectations and understanding of the reader, but putting oneself in the reader's place to realize the crucial role of completeness, conciseness, clarity, accuracy, and readability. 1 These naturally self-centred youths have written to captive audiences all their lives: parents, who love them and will read anything hoping for more, and teachers, who are paid to read anything no matter how bad. Parents, having surrendered the education of their children to professionals, are unlikely to take back what may be the most difficult task--getting them to write effectively. Teachers at all levels, even those who teach English, feel they have enough to do in teaching the subject matter without improving standards of student presentation. Most people deplore poor writing, fewer know how to improve it, fewer still can show others how to improve, and very few indeed enjoy showing others how to improve their writing. Like cleaning the garage or ironing clothes, teaching writing has its major reward in the result rather than the process. If teaching writing were great fun, graduate students in English departments would teach literature instead of composition courses and my department would not have assigned its most junior member on sabbatical to teach the new report writing course eleven years ago.

Report writing began at Waterloo with fifteen students and grew very quickly to 500 students per year on campus and by correspondence with demand for up to twice that number. Students came from as many as 35 departments in 6 faculties in any one term. A growing number of departments have required their students to take this course. 
Administrators in the engineering faculty have threatened me with 3000 students a year. We have turned away students for lack of space and teaching resources every term since that first class of 15 . If every one in our 22-member department taught three sections of 25 students three terms a year we could meet half the known demand for report writing. Instead two professors teach the course, one in fall and one in winter term with the assistance of graduate students. In addition, the professors train the T.A.S to teach the course for the spring term and one acts as a resource person for them. At first, because of the popularity of the course among students and the refusal of other faculty to teach it, I could demand one T.A. for every 15 students. As the student-facuity ratio eroded from $11 / 1$ to $23 / 1$ across the university my section sizes grew to 25. Full-time graduate students may work no more than ten hours a week or risk losing the graduate fellowships. That polite fiction was strained beyond reason when their tutoring and marking time rose significantly over 20 hours a week. Continuing pressure on the course to grow, combined with falling graduate enrolment and financial constraints, forced me to reduce the assignments in the course, over several years, from eight original submissions and three revisions to five originals and one revision. Because I considered revision crucial, I removed most short report forms and concentrated on the long formal report and its preliminary steps--the proposal, definition and description, progress report, and outline and semi-final draft--thereby allowing students to approach the subject of their choice six times with ever increasing refinement.

I received some help. Increasing entrance standards in all faculties improved the general level of student writing. Also, I was permitted to make the introductory essay course or its equivalent an understood prerequisite for the report writing course. But still the students came, better prepared and more highly motivated though they were, in numbers we could not accommodate.

What do these students and/or the faculty who send them really want from the course? They don't want to learn how to write reports; they have been writing lab reports, field reports, work reports, information reports, research reports, etc. ever since they arrived at university. They really want (or the faculty want them to achieve) the ability to write complete, concise, clear, accurate, readable reports. In other words, they need to learn how to revise effectively. The other aspects of report writing--defining the problem, planning and conducting the research, analyzing data, reaching conclusions, organizing and writing up the results--students can and often do learn in courses in their own departments. But nowhere else does anyone teach how to apply their critical skills to make a poor or mediocre report into a good one.

I enjoy helping students learn to revise, but I resent correcting writing problems they should have left far behind: spelling errors, sloppy diction, incomplete sentences, and other evidence of carelessness and inadequate self-criticism. Instead of spending all my marking time suggesting rewording for brevity, strength, better psychology and 
improved audience appeal, I spend almost $40 \%$ of the time correcting errors my sixth grade teacher wouldn't allow. A few faculty members in science and engineering submit their students' papers to tutors, in the writing clinic or ESL program, then return the papers to the student for revision before final submission. Administrative opposition to the extra cost has prevented the practice from spreading. But if a computer can do that ... Why not? Waterloo, after all, is the computer university. Over half the students at the University and in the Report Writing course are Co-op students. Over $90 \%$ of those students have experience with computers on the job by the time they graduate and will in all likelihood continue to use computers. Over $80 \%$ of Arts Co-op students use wordprocessors on the job before they graduate and any experience they can get with wordprocessors in their courses will help in their job placements. For some time now my colleagues and I have recognized that students using the computer to reproduce their papers have submitted cleaner, neater, more error-free assignments and have far less resistance to revising, both before and after submitting the paper. When I discovered that portions of Bell Labs' Writer's Workbench were on the UNIX system in the Arts Computing facility, I decided to test my theory that using the computer would provide better results in less time for all students, giving teachers a chance to spend their marking time on something more sophisticated than spelling, basic diction, and wordiness.

This past year I used the Workbench programs SPELL and CORRECT, STYLE, and DICTION, developed for Bell Labs by L.L. Cherry of AT\&T and W. Vesterman of Rutgers. The SPELL program identifies and lists spelling mistakes in a document by comparing the works in the text with its American or British dictionary and identifying those which do not match. However, it has limitations; it does not recognize as spelling mistakes words spelled like other words, especially homophones such as there/their, its/it's, and typographical errors which, by misspelling one word, spell another recognizable English word. It also lists all proper nouns. Even so, the program catches inany student spelling mistakes or typographical errors. The interactive CORRECT program goes one step further and therefore students use it more of ten. It scans the document to find non-matching words, then prompts the user to change.

The DICTION program locates wordy phrases and multisyllabic replacements for simpler words. It has a group of 450 phrases as a default list (see Table 1) which the teacher or user can revise to include other phrases or omit items. The program matches words and phrases in the text with those of its phrase bank and lists the sentences affected with the matching items bracketed. The command EXPLAIN invokes an interactive thesaurus with illustrated uses of the alternatives. 


\section{TABLE 1}

\section{Samples from Default DICTION Patterns}
a majority of
abovementioned
absolutely essential
accordingly
afford an opportunity
any and all
as good or better than
as per
at this point in time
being as
be cognizant of
close proximity
common accord
conjecture
consensus of opinion
deleterious effect
desirable benefits
enter into
experiencing difficulty
facilitate
final outcome
for the purpose of
in conjunction with
in the interim
in rare cases
in the last analysis
literally
mutual cooperation
necessary requisite
necessitate
notwithstanding
of the opinion that
on the grounds that
past history
physical size
plan ahead
prioritize
procure
reason why
substantially in agreement
surrounding circumstances
take into consideration
the foreseeable future
total effect of all this
try and
ultimate end
utilize
with regard to
with this in mind
otherwise 
The STYLE program analyzes the surface characteristics of the writing style of a document and prints a summary of readability indices, sentence length and type, word usage, and sentence openers (see Table 2). It can also locate all sentences over or under certain lengths, of readability index higher than a given number, those containing a passive verb, or those beginning with an expletive. After using the Writer's Workbench programs to identify writing problems, the students can correct their documents easily on the system before submitting anything to the teacher. The assistance programs and easy editing capacity of the computer allow students to improve certain aspects of their writing "free"--that is without the "punishment" of a shocking mark or copious red penciling. They can improve their assignments themselves in much the same way that we do the laundry or make a meal ourselves--the washer, dryer, stove, dishwasher, or computer program don't count. After revising the document, students can format it and produce a file or a paper copy, depending on the demands of the reader. (Next Fall English Co-op Year II students will have IBM CMS Script GML accounts and submit their assignments by computer mail to their instructors accounts.) Assignments submitted on paper can come from the line printer, the Diablo (a selectric typewriter with carbon ribbon and a variety of typeballs), a laser printer, or a photo compositor with up to 80 fonts.

Here we have the theoretical brave new world of teaching, writing especially, using computers, wordprocessors, and writing programs. Did you hear me right? Did I say theoretical? Alas, I did indeed! The practical world has unfortunate realities, which begin for the student with the problem of accessibility. To use wordprocessing and Writer's Workbench programs, students must learn how to sign up on a computer and to use the commands that the particular wordprocessor demands. Various computer systems are more or less easy to sign up on, various wordprocessors more or less easy to use. The University of Waterloo has 3 major mainframe computers: IBM, Digital Equipment Corporation (DEC), and Honeywell in addition to hundreds of personal computers available, some tied together into networks of PCs with or without a line to the mainframe, with or without printing facilities. Most computer use now is course-centred or assignment-centred. In almost any class of report writing students, one will find students of widely varying computer experience, from students who know two or three systems aleady to students who have had no contact with computers at all, which makes teaching computer skills lessons difficult. The difficulty of introducing into a report writing course in the English Department a short course in use of the computer is greatly exacerbated by using DEC's UNIX system, which is not noted for user friendliness. Writer's Workbench works only on UNIX, and therefore all students must use UNIX to gain access to the STYLE, DICTION, and SPELL programs. Trying to teach a new computer and wordprocessing system to a group of students, some of whom have no experience and some of whom want to know why they can't use their Wordstar or Scripsit or Electric Pencil that they've been using in their own home for 4 or 5 years, and other students who loudly claim that the wordprocessing on the JANET network or the IBM or 


\section{TABLE 2}

Sample STYLE Analysis

readability grades:

(Kincaid) 13.2 (auto) 14.7 (Coleman-Liau) 12.5 (Flesch) 13.7 (45.1)

sentence info:

no. sent 140 no. wds 3517

av sent leng 25.1 av word leng 5.01

no. questions 5 no. imperatives 0

no. nonfunc wds $211160.0 \%$ av leng 6.37

short sent $(<20) \quad 34 \%$ (48) long sent (>35) 19\% (27)

longest sent 80 wds at sent 79 ; shortest sent 3 wds at sent 129

sentence types:

simple $40 \%$ (56) complex $30 \%$ (42)

compound $10 \%$ (14) compound-complex 20\% (28)

word usage:

verb types as $\%$ of total verbs

tobe $10 \%$ (36) aux $23 \%(80)$ inf $25 \%$ (89)

passives as \% of non-inf verbs $3 \%(7)$

types as $\%$ of total

prep $10.7 \%$ (376) conj 5.2\% (184) adv 3.9\% (138)

noun $28.9 \%$ (1016) adj $17.7 \%$ (624) pron $5.7 \%$ (201)

nominalizations $2 \%(75)$

sentence beginnings:

subject opener: noun (26) pron (18) pos (4) adj (16) art (23) tot $62 \%$ prep 14\% (19) adv 11\% (16)

verb $2 \%$ (3) sub-conj $7 \%(10)$ conj $3 \%$ (4)

expletives $1 \%$ (1) 
Honeywell mainframe is much better can be a real challenge. Once the students learn the basics of the system, they need to be able to use it. Therein lies another problem. Students like to write papers at the last minute, despite our best advice; when they try to do that on the UNIX system they find everyone else trying to get onto the system. Students far outnumber available lines; therefore students have to use the computer all hours of the night as well as the day. They could use other wordprocessing systems on other computers and then transfer the material thereby reducing time on UNIX, but in that case they would need an account in two computer systems and the knowledge of how to transfer documents back and forth between the systems, not an easy task yet.

began using the wordprocessor and Writer's Workbench programs in a pilot. study with 40 students in a special chartered accountancy program, al? highly motivated over-achievers, and most rather highly regimented as well. They complained about access to the system, the difficulty of the editor, the low quality of the printout, and all the while they produced what I asked of them. All but two students who had their own microcomputer on campus used UNIX and the Workbench programs for five of their assignments.

At the beginning of term I announced my longstanding policy on revision: any student may revise any paper and I will remark it and award the revised mark. In my view students often learn more revising a paper than writing it. My revision policy has meant $15 \%$ extra marking but has greatly increased satisfaction and a sense, of justice. Last year the chartered accountancy students, in their drive for excellence (and high marks) had created $30 \%$ extra marking, so I prepared my T.A. and myself for even more marking of revisions, up to 50 or $60 \%$. But, having worked with these students before, we looked forward to marking neatly typed papers free of simple mechanical errors. Before long we realized we had provided the students with a free editing and proofreading service. If the marks on the returned papers did not satisfy the students, they would make the suggested revisions using the wordprocessor and submit the revised version for marking. Instead of marking 240 papers (six papers for 40 students), we marked over 700. The students learned a valuable lesson about the value of revision and the ease of using a wordprocessor; their instructors may have learned even more.

However, a followup questionnaire shows that in the following term, no one who had knowledge of any other wordprocessing system used the UNIX system again. Even those who knew no other wordprocessing system used a typewriter or handwriting as opposed to UNIX more than $50 \%$ of the time. Difficulty in finding a vacant access terminal and getting online combined with the low user friendliness and low wordprocessing power to discourage students from using UNIX, even with Writer's Workbench, when they could use CMS Script. Then why not use IBM's writer's package? Because EPISTLE, a $\$ 200,000$ a year (estimated) fancy version of Bell's Workbench (a $\$ 2000$ one-time cost) is still on the drawing board and neither the University of Waterloo nor IBM will fund it. 
I have spoken of the advantage to students of having a machine do "free" correction of their writing; many students feel that way. However, some students used UNIX to format and edit the document and SPELL to avoid spelling errors, but avoided DICTION and STYLE. Questioning them, I found they resented criticism from a machine, especially when the assigning professor found no fault. They get enough criticism without soliciting more.

The experiment in the winter term using a report writing class with a typical mix of students (22 departments, six faculties) corroborated the results of the first test. I insisted that students in my tutorial group use the programs and only one refused. My T.A.s found student use of the wordprocessor directly proportional to the T.A.'s previous experience with computers and his/her degree of enthusiasm in supporting my recommendations. The T.A. with no previous wordprocessing experience and some doubts about its effectiveness only convinced one third of his students to use the computer, even though I had made it an informal requirement. Those students who made the effort to learn how to use the system used it for many of their other assignments as well. These results confirm experience across the University (e.g. Environmental Studies, Mechanical Engineering, Applied Arts Co-op) and in the U.S.2 The structure of the course and timetabling demands did not allow me to isolate wordprocessing as a single variable. Even though we have no hard data, my T.A.s and I agree that those who continued to use the wordprocessor and writing programs revised more, produced better reports, and felt better about the final results.

The STYLE and DICTION programs present two potential dangers to good writing. The words in the default diction file and the type of style analysis in the programs may have a levelling influence, encouraging poor writers to improve and fine writers to conform. However, the best writers in the special accounting class assured me that they had no hesitation in resisting suggested revision.

By adding or deleting phrases in DICTION, teachers can give computer authority to personal preferences, but recognition of the possibility should allow teachers to guard against such bias. Bias creeps in more subtly in helping students to interpret the STYLE analysis. Setting arbitrary limits such as readability, index maxima and minima, and acceptable percentages of passives, "to be" verbs and nominalizations, although tempting and easy, may prove unwise. As a longstanding opponent of overuse of the passive I have suggested that students aim to reduce "to be" verbs below $1 \%$ of total words as one technique in using active voice and achieving concise expression. Finding passive and "to be" verbs as a percentage of verbs (making the percentage much higher) came as an answer to prayer in the active voice. However, any teacher who cannot meet such temptations with reasonable restraint will run afoul of his/her students without computer assistance. 
Using the computer to assist in teaching report writing has not meant an easing of my workload, but I have been able to spend my time in more interesting ways than marking the same simple errors of carelessness repeatedly. Using the wordprocessor and writing assistance programs has helped students to become more independent in their writing and to resist revision less virulently. Papers delivered at the MLA last December (see footnote 2) suggested that students using wordprocessors did not write better after one term than students who composed on paper. However, they will learn to revise more; the wordprocessor removes the major barrier to adequate revision--having to recopy the piece to have a clean copy. But my report writing students have a new barrier--difficult access to the system and unfriendly software. Next year at this time those barriers too will vanish.

And what lies beyond? Since beginning to prepare this paper two proposals have emerged which, if they come to fruition, will change not only the teaching of writing but all teaching and learning at Waterloo:

1. A new B.A. program in technical writing with technical subject options (e.g. biology, computer science, political science).

2. Tenders for an new microcomputer

512K RAM - room to type in Paradise Lost.

1 megabyte hard disk storage--space to store Paradise

Regained, Samson Agonistes, Hamlet and King Lear ds well as Paradise Lost.

Flip up flat screen with 20 lines 80 characters long, colour graphics capability.

RS 232 interface to allow signing up on other computers or attaching a printer.

Size: small portable typewriter.

Weight: $5-10$ pounds.

Price: under $\$ 2000$.

Intention: to produce test machines for classes--30 by Sept. 85,300 by Jan. 86,3000 by Sept. 86 and 20,000, one for every student and faculty member to lease or buy, within four years.

Would anyone care to predict the effect?

\section{NOTES}

1. William J. Gallagher uses these criteria for revision in Report Writing for Management (Reading, Mass.: Addison-Wesley, 1968), pp. $77 \mathrm{ff}$. 
2. Papers presented at Session 322 of MLA 1984: Donald Ross (Arkansas Tech.) "Computers and the Teaching of Composition," Deborah Holdstein (Illinois Institute of Technology) "Combining Computer-aided Instruction and Wordprocessing," and Geoffrey Sirc (University of Minnesota - Minneapolis) "A Computer Tool for Analyzing the Composing Process."

Robert Gosselink teaches literature and technical writing in the Department of English, University of Waterloo. 